\title{
Chapter 4 \\ Public Preferences About Fairness \\ and the Ethics of Allocating Scarce Medical \\ Interventions
}

\author{
Govind Persad
}

\section{Introduction}

When there are not enough medical resources to go around, society faces the question of how to fairly allocate them. And when these resources are not only scarce but essential to treat a potentially deadly condition, fair allocation becomes a question of-as Life magazine once put it_deciding "who lives, who dies" (Alexander, 1962). These questions have prompted attention and reflection from medical professionals, ethicists, theologians, and the general public.

Some scholars, frequently social scientists, have conducted survey or focusgroup research on various groups' preferences regarding how scarce medical resources should be allocated. My focus in this chapter is to examine how socialscientific research on public preferences bears on the ethical question of how those resources should in fact be allocated, and explain how social-scientific researchers might find an understanding of work in ethics useful as they design mechanisms for data collection and analysis. I proceed by first distinguishing the methodologies of social science and ethics. I then provide an overview of different approaches to the ethics of allocating scarce medical interventions, including an approach-the complete lives system - which I have previously defended, and a brief recap of socialscientific research on the allocation of scarce medical resources. Following these overviews, I examine different ways in which public preferences could matter to the ethics of allocation. Last, I suggest some ways in which social scientists could learn from ethics as they conduct research into public preferences regarding the allocation of scarce medical resources.

\footnotetext{
G. Persad (ه)

Berman Institute of Bioethics, Johns Hopkins University, Baltimore, MD, USA

Department of Health Policy and Management, Bloomberg School of Public Health,

Johns Hopkins University, Baltimore, MD, USA

e-mail: gpersad@jhu.edu
} 


\section{Normative Versus Empirical Methodologies}

The allocation of scarce medical resources, such as transplantable organs or vaccines in a pandemic, involves answering both normative and descriptive questions. Answering descriptive questions involves determining what is happening in the world, or what will likely happen as a result of certain choices. For example, allocating antiviral medication during an influenza pandemic involves answering the descriptive question of whether allocating medication to the people who are sickest right now is likely to save the most lives. In this chapter, the descriptive questions discussed will primarily involve research into people's values or preferences: whether the general public, or subgroups such as influenza patients, will approve of a policy that allocates that medication to the people who are sickest right now. Even though this research solicits opinions regarding what should happen, it is fundamentally descriptive rather than normative, because it does not try to answer the question of what in fact should happen, but instead reports individuals' preferences regarding what should happen. Such research fits the model described by Daniel Sulmasy and Jeremy Sugarman as "descriptive ethics," which "asks empirical questions such as, How do people think they ought to act in this particular situation of normative concern? What facts are relevant to this particular ethical inquiry? How do people actually behave in this particular circumstance of ethical concern?" (2001). What Sulmasy and Sugarman call "descriptive ethics" encompasses the identification both of what social scientists call descriptive norms, which refer to what people actually do, and prescriptive norms, which refer to what people believe they ought to do. Even when social scientists study prescriptive norms, they are describing what those norms and thereby making claims about how the world is, rather than making claims about how the world should be. Descriptive questionsin Sulmasy and Sugarman's sense-are typically answered using a scientific or social-scientific methodology.

In contrast, normative questions concern what outcomes should happen-for instance, whether we should allocate antiviral medication in ways that saves the most lives, or should instead allocate it on a first-come, first-served basis-and are addressed using methodologies within ethics rather than within the social sciences. Rather than identifying descriptive norms (what people actually do) or prescriptive norms (what people believe they should do), answering normative questions involves determining what people in fact should do. Familiar normative questions we answer for ourselves in daily life include whether we ought to help one person rather than another, or whether we are permitted to deceive someone for the sake of the greater good. In a medical context, an example of a normative question is whether we should allocate antiviral medication in a way that saves the most lives, or should instead allocate it in a way that gives everyone an equal chance of receiving medication.

Ethics offers a variety of approaches to answering normative questions. Utilitarianism, for instance, simply asks us to add up the benefits and burdens produced by a given intervention, and then tells us that we should do whatever produces 
the best balance of benefits over burdens. Other prominent approaches in biomedical ethics include principlism (which evaluates outcomes in terms of how well they realize beneficence, non-maleficence, autonomy, and justice), reflective equilibrium (which begins with our intuitive ethical responses to cases and then asks us to consider how well they cohere with one another upon reflection), and virtue ethics (which evaluates outcomes by comparing them to the decisions that a virtuous person would reach) (Sulmasy \& Sugarman, 2001).

Ethical approaches often agree in many ways-for instance, most agree that we should avoid killing innocent people. However, there are also important points of disagreement. For instance, utilitarian approaches are more willing than many other approaches to countenance harming a smaller number of people in order to promote the good of a greater number of people. It may appear that ethics stands apart from the social sciences in its lack of consensus on methodology. However, disagreements about the proper methodology for answering normative questions are not so different from disagreements about the proper social-scientific method for answering certain descriptive questions, such as disagreements between Bayesian and frequentist statisticians (Malakoff, 1999) or disagreements between economists and sociologists.

Much social-scientific research on the allocation of scarce medical interventions makes tacit assumptions about normative questions: for instance, that maximizing a certain outcome (such as lives saved) is morally desirable, or that we ought to allocate scarce medical resources in ways that the general public approves of. Social scientists often do not examine these assumptions in depth. Part of this chapter's project is to identify and investigate these normative assumptions, as well as to explain what role descriptive research into public preferences can play in answering normative questions.

\section{Ethical Principles for Fairly Allocating Scarce Medical Resources}

In a prior article, I and two coauthors discussed several ethical principles proposed for the allocation of scarce medical resources (Persad, Wertheimer, \& Emanuel, 2009). I adopt the same division of those principles here: maximizing total benefit, treating people equally, helping the worst-off, and promoting and rewarding usefulness.

Two ways of maximizing total benefit are to aim at saving the most lives, and to aim at saving the most life-years. While these goals sometimes go together, they can come apart: one article notes that "in the case of pandemic influenza, it is clear that unless vaccines are so plentiful that transmission can be completely or nearly halted, policies to minimize total mortality may differ from those to minimize years of life lost or disability-adjusted years of life lost" (Lipsitch, et al., 2011). Another study observes that bilateral lung transplantation (i.e., transplanting two lungs into a 
single person) can sometimes save more future life-years, even while transplanting lungs singly enables more people to receive transplants and thus saves more lives (Munson, Christie, \& Halpern, 2011). Of course, the goal of minimizing deaths is ultimately unachievable, since everyone dies in the end (Chappell, 2016). The choice between maximizing lives saved and life-years saved is ultimately between providing a lesser number of life-years to a larger number of people and a greater number of life-years to a smaller number of people.

The two most prominent ways of treating people equally are random selection and first-come, first-served selection. Random selection ensures each person has the exact same chance of receiving the benefit. One way of conducting random selection is to conduct a lottery in which each person is assigned a number at random and then scarce interventions are provided to individuals with certain numbers. It is also possible to use other socially insignificant identifiers to implement random selection, such as the day of the week someone was born or the last digit of their social security number. First-come, first-served selection is often regarded as a way of treating people equally without random selection. However, some aspects of firstcome, first-served selection suggest that it does not genuinely treat people equally, including time wasted in queuing and unfairness to individuals who lack the time to wait in line or who die while waiting. The latter unfairness threatens the ability of first-come, first-served allocation to genuinely treat people equally.

Another common value is helping the worst-off, which I understand to mean those who will be worst-off if they do not receive interventions. Some believe that those who are the sickest right now (i.e., most likely to die if they do not receive scarce resources) are the worst-off. However, if we take a lifetime rather than a momentary perspective on disadvantage, those who are in the greatest danger of dying right now are frequently not the worst-off when we consider their lives as a whole. For example, because living to only 25 is worse than living to 75 , a 24-yearold who will die in a year unless she receives a scarce resource is worse off than a 74-year-old who will die tomorrow if she does not receive that resource. While sickest-first allocation can make sense when scarcity is only short term, it is less attractive when scarcity will persist for a long time. Accordingly, when scarcity is persistent, those who are in danger of dying early in life should receive priority over those who have already enjoyed many years of life but are in danger of dying soon if not helped. As the human rights scholar Alicia Yamin (2009) puts it, "An adequate rights framework must take account of intergenerational equity including the equal opportunity of younger people to live as long as older people already have" (p. 5).

Allocation according to instrumental value (usefulness) prioritizes individuals who have been helpful contributors to society in the past, or who are likely to be helpful contributors in the future. Unlike the prior principles discussed, allocation according to future contribution does not regard the set of resources available as a fixed quantity: rather, it allocates more to some people in order to achieve a larger total quantity of the scarce intervention or of other social goods. An example would be allocating antiviral medication preferentially to front-line health care workers responding to a viral pandemic, as was done during the recent Ebola outbreak (Rid $\&$ Emanuel, 2014). This allocation was justifiable because these workers could help 
many more patients once recovered. However, individuals who are most able to effectively contribute to society are also likely to be better-off in other ways, which means that allocation according to future contribution could exacerbate inequality, particularly if skilled health care workers are favored over family members who provide care. Meanwhile, allocation according to past conduct can be justified on the basis that it will encourage individuals to contribute to society, but also on the basis that past contributors acquire a reciprocity-based moral entitlement (or disentitlement) to assistance. One question posed by allocation according to past conduct involves defining what counts as a helpful contribution: does leading a healthy or law-abiding lifestyle count as a helpful contribution, and should it entitle people to priority?

One prominent principle we did not discuss is ability-to-pay allocation, where people can purchase access to scarce medical resources by outbidding others for those resources. Economic theory might appear to support ability-to-pay allocation as an effective way of eliciting individuals' capacity to benefit, on the principle that people who stand to benefit more from a resource will be willing to pay more for that resource. However, while ability-to-pay allocation has some merit for heterogeneous goods that are not immediately lifesaving, such as foodstuffs or clothing, it is a poor way of allocating lifesaving medical resources such as antiviral medications or transplantable organs. Most importantly, ability to pay reflects prior wealth, which is a poor proxy for ability to benefit, and which entrenches and amplifies existing social divisions. Additionally, those with poor prospects of benefiting from a scarce, lifesaving resource are unlikely to have a lower willingness to pay for the resource, since they will be dead without the resource (and so unable to use the money they saved). For this reason, ability-to-pay allocation is unattractive where the stakes of receiving an intervention are great and resources are absolutely scarce. Ability to pay is more appealing, though still controversial, for physician, pharmaceutical, and hospital services where no scarcity exists and the stakes, while significant, are lower (Krohmal \& Emanuel, 2007). Some national health care systems, like that in the United States, are friendlier to ability-to-pay allocation, while others are less so.

Another principle we dismissed as morally untenable is identity-based allocation, where people receive scarce resources based on their membership in identity categories such as race, gender, national origin, or religion. These criteria have all the benefit-maximization disadvantages of pure lottery allocation, and, much more seriously, entrench societal divisions and threaten civic equality.

Ultimately, none of the principles we discuss are likely to be sufficient on their own for a fair allocation of resources. This suggests the attractiveness of approaches that combine one or more of the principles, such as the approach we call the "complete lives system." This system includes both benefit-maximizing principles (saving the most lives and saving the most life-years). However, it includes the other principles (giving priority to the worst-off, treating people equally, and promoting usefulness) only in specified ways: it favors the worst-off through a modified youngest-first system that weights age in a way that gives highest priority to children and adolescents; excludes first-come, first-served allocation; and allows 
promotion of usefulness only when the beneficiaries are front-line medical workers. Real-world approaches to allocating medical resources also balance different principles against one another: as an example, current rules for lung allocation balance the urgency of a problem against the medical benefit of that problem (Egan et al., 2006).

Though the general strategy of adopting a multi-principle approach to allocation has met little resistance, some specifics of the complete lives system have been criticized by commentators. Some have argued that more priority should be given to very young children, rather than adolescents (Gamlund, 2016). Others have argued that we should replace the principle of saving the most life-years with a principle that considers quality of life (McMillan \& Hope, 2010; Norheim, 2010; Ottersen, 2013). Still others argue that we should understand the worst-off to be the people who are sickest right now rather than those in danger of dying young (Kerstein \& Bognar, 2010). Some have also defended first-come, first-served allocation as equal to or better than a lottery (McMillan \& Hope, 2010).

Though we continue to defend our view, many of the critics' emendations would also generate reasonable systems for allocation. It would be reasonable to adjust the degree of priority given to very young children upward or downward, or to give greater weight to saving the most life-years than to saving lives. It might also be reasonable to employ a first-come, first-served allocation approach rather than a lottery approach if first-come, first-served can be designed to prevent serious unfairness.

However, the inclusion of certain principles - many of which are popular in realworld politics-would lead to allocation systems that are seriously deficient. The most important example is the inclusion of sickest-first principles, which come close to being a simple mistake of fact if they assume that those who are less sick will be saved later on. Another change that would lead to a deficient system would be the exclusion of any priority for younger individuals. Even though the precise degree and scope of that priority can reasonably be debated, the importance of saving more life-years and protecting the worst-off-those who will die young if not helped-both favor giving priority to younger people. From a perspective of fairness to individuals, ability-to-pay and identity-based allocation must also be rejected.

\section{Public Attitudes Regarding the Allocation of Scarce Medical Resources}

Social scientists have employed a variety of methodologies to assess public preferences regarding the allocation of scarce medical resources. Some have circulated surveys to laypeople (Krütli, Rosemann, Tornblom, \& Smieszek, 2016; Tong et al., 2010, 2012, 2013), while others have surveyed medical professionals (Strech, Synofzik, \& Marckmann, 2008). Still others have conducted qualitative research, 
based on transcripts from focus groups or deliberative fora (Irving et al., 2013; Vawter et al., 2010; Vawter, Gervais, \& Garrett, 2007). Other researchers have attempted to identify the neurological processes underlying decision-making about the allocation of scarce medical resources, or have studied whether psychological influences cause judgments about allocation to shift (Lenton, Blair, \& Hastie, 2006; Smith, Anand, Benattayallah, \& Hodgson, 2015). Most research focuses on the allocation of specific scarce resources, such as transplantable organs, intensive care unit beds, or vaccines in a pandemic, though some research focuses on public preferences for resource allocation more generally.

Surveys have found a wide range of public preferences though they generally agree on certain points. There is some preference for allocation to individuals who start off being more severely ill or otherwise worse-off; to younger patients rather than older ones; to individuals with dependents; and to those who are not perceived to have been culpable for their own ill health.

\section{How Are Public Attitudes Relevant to Ethical Questions?}

The social-scientific research briefly described in the prior section attempts to answer a descriptive question: what are people's beliefs about how medical resources should be allocated? However, society is ultimately interested not only in empirical surveys of how its members believe medical interventions should be allocated, but also in answers to the normative question of how medical resources should be allocated. This section will examine what bearing the answer to the descriptive question might have on the answer to the normative question.

\section{Public Attitudes as an Answer to the Normative Question: Relativism}

Some have suggested that answering questions such as "How should society allocate scarce medical resources?" simply involves determining how most people in the relevant society would answer those questions. On this understanding, normative questions can be answered using descriptive, survey-based methods.

This approach faces two serious problems. First, it cannot explain how societies can make moral mistakes or progress morally. For instance, when slavery was legal in the United States, it is plausible that individuals would have believed that slaves should not have received scarce medical resources. However, these beliefs-while understandable given the context of their time-were mistaken, and their abandonment was a form of moral progress. An approach that equates ethical correctness with popular acceptance cannot explain these facts. Second, it is inconsistent with its own methodology. When respondents in surveys or focus groups answer the 
normative question "How should society allocate scarce medical resources?" they do so not by looking to surveys of others' attitudes, but rather by engaging in some form of moral deliberation. In this respect, research on public attitudes is just as limited a methodology for answering normative questions as it is for answering factual questions in the sciences and social sciences. Asking people whether infant mortality is falling, or whether sea levels are rising, is the wrong approach to answering those factual questions.

Ultimately, while social-scientific research is an effective methodology for collecting public attitudes regarding normative questions, its very design concedes that moral deliberation - not surveys of public attitudes - is the correct methodology for answering normative questions. As Sulmasy and Sugarman observe, "The opinion survey, a commonly used empirical technique in medical ethics, should never be construed to give 'the answer.' ... The mere fact that almost everyone says that something is proper, or that almost everyone acts in a certain way, does not make it proper to act that way" (2001, pp. 8-9).

\section{Expert Attitudes as an Answer to the Normative Question: Scientism}

Another approach to answering normative questions is to treat surveys of experts, rather than surveys of the general public, as normatively authoritative. Where questions of technical expertise are at issue, such as which immunosuppressants are most likely to prevent an organ from being rejected, there is a clear difference between the weight we should give to surveys of medical professionals and surveys of laypeople. However, the question of how society should allocate scarce medical resources is not a technical question whose answers can be discovered via the methods of laboratory science: it is a question of values (Hope, Sprigings, \& Crisp, 1993).

Some might object that medical professionals are not merely technical experts, but also experts in the craft or activity of medicine-an activity that also involves considering questions of value. However, it is doubtful that medical professionals have special expertise in the sorts of value questions involved in the allocation of scarce medical resources. Medical professionals, indeed, are often discouraged from thinking about value questions at a societal level and instead encouraged to see themselves as obliged to look out for the interests of individual patients.

\section{Public Attitudes as an Entry Point for Moral Inquiry}

That research on either public or expert attitudes cannot tell us the answer to normative questions might suggest that such research is irrelevant to normative questions. The ethicist Frances Kamm displays this attitude when she suggests: 
In general, the approach to deriving moral principles that I adopt may be described as follows: Consider as many case-based judgments of yours as prove necessary. Do not ignore some case-based judgments, assuming they are errors, just because they conflict with simple or intuitively plausible principles that account for some subset of your case-based judgments. Work on the assumption that a different principle can account for all the judgments. Be prepared to be surprised as to what this principle is. Remember that this principle can be simple, even though it is discovered by considering many complex cases...Then, consider the principle on its own, to see if it expresses some plausible value or conception of the person or relations between persons. This is necessary to justify it as a correct principle, one that has normative weight, not merely one that makes all the case judgments cohere...I say, consider your case-based judgments, rather than do a survey of everyone's judgments. This is because I believe that much more is accomplished when one person considers her judgments and then tries to analyze and justify their grounds than if we do mere surveys (2007, p. 5).

Skepticism about surveys as a basis for ethical claims is not unique to Kamm and others who share her non-consequentialist, case-based methodology for answering questions of value. Many consequentialist moral philosophers, who reach conclusions diametrically opposite from Kamm's, also reject the claim that surveys tell us what is valuable. They instead contend that certain basic claims are morally obvious - such as the idea that we should extend lives as much as possible-and that claims about how scarce medical resources should be allocated must build on these obvious facts.

Kamm and others are correct that surveys do not tell us what is right and wrong. As Allen Alvarez puts it, "Empirical investigation, e.g., surveys or ethnographies, can be methodologically appropriate in determining what people actually value. But in understanding, analyzing, solving, and communicating moral problems, the most appropriate approach would be philosophical reasoning or reflection" (2001, p. 518).

Even though public attitudes do not directly determine the solution to moral problems, empirical research into public attitudes can be useful in a variety of ways. By showing which beliefs are popular among the public, or which beliefs are points of division, empirical research can help to focus moral inquiry on those claims or beliefs, thereby ensuring that philosophical reasoning is relevant to real-world problems. Furthermore, even though popularity does not constitute correctness, the unpopularity of a normative position can justify placing it under scrutiny. The idea that an unpopular position is less likely to be correct is bolstered by the Condorcet Jury Theorem, which suggests that individuals forming beliefs independently who are each more likely to get things right than not are highly likely, as a large group, to get things right. This theorem depends in its original form on the assumption-frequently falsified in practice-that individuals form beliefs independently of one another, although some have suggested that it can hold even if there is some interdependence as well (Estlund, 1994). Lastly, research that elucidates not only people's beliefs but their reasons for holding those beliefs can help in developing arguments in favor of certain allocation systems. 


\section{How Are Public Attitudes Relevant to the Implementation of Allocation Systems?}

Even though public attitudes have only an indirect role with respect to the question of how scarce medical resources should be allocated, they have a greater role in discussions of how allocation systems should be implemented. This section reviews three ways in which public attitudes can be relevant to implementation: as constraints on justice, as requirements of public reason, or as requirements for implementability.

\section{Public Preferences as Constraints on Justice}

Even if a proposed allocation policy appears normatively attractive, certain allocation policies may be practically difficult or impossible to implement because people will be unable or unwilling to go along with the policies. This raises a question about the interplay between the normative question of rightness and the empirical question of what is possible for individuals in society to achieve.

John Rawls is notable for defending the view that a just policy must be one that is implementable given empirical facts about human capacities, including psychological capacities. For Rawls (1999), part of justice is attainability, and if a policy could only be adopted and sustained by superhuman individuals-for instance, if it requires unlimited altruism or sociability — then it is not just but instead beyond justice. In contrast, G.A. Cohen has argued that fairness should be evaluated without reference to individuals' capacity to do what is fair. Considering human capacities should be done at a later stage, and should not be part of normative inquiry into what is just (Cohen, 2009).

If Rawls's account of justice is correct, empirical research into public attitudes can be relevant in helping to establish the limits of attitudes - such as altruismthat are necessary for allocation systems to function. In contrast, if Cohen's account is correct, Rawls's concerns about human capacities are really concerns about the implementability of justice (discussed later in this section), not about justice itself.

\section{Public Attitudes as Constraints on Implementation: Public Reason}

Rawls is also well known for his idea of “public reason.” On Rawls's (2005) view, legislative judgments regarding "constitutional essentials and matters of basic justice" - a set which likely includes judgments about the allocation of scarce medical resources-must be justified by appeal to public reasons. Rawls defines public 
reasons as reasons that the decisionmaker proffering them can reasonably expect that others will reasonably accept. On a Rawlsian view, even if a decisionmaker believes that allocating medical resources in a certain way is morally right, she needs to be able to frame that allocation in a way that appeal to public reasons and values. Public reason approaches will make empirical research into public attitudes more relevant, because alternative allocation systems that are reasonable and widely popular will need to be addressed in public debate by those favoring other systems they believe are morally best.

In contrast, some reject public reason in favor of the view that individuals in charge of making decisions in society should simply do what is morally correct, even if others could not be expected to understand or accept those choices. These are often termed perfectionist or comprehensive approaches. On these approaches, empirical research into public attitudes will only be relevant if it affects what is morally correct: once we have determined what to do, we should do it even if it conflicts with reasonable public attitudes. So, for instance, if using a lottery to allocate scarce medical resources turns out to be morally correct, decisionmakers should use lotteries even if the public strongly prefers first-come, first-served allocation and is reasonable in holding to its preference.

\section{Public Preferences as Implementation Constraints: Real-World Implementability}

Even if a system of allocation is morally correct, publicly reasonable, and achievable for individuals, public endorsement may still matter in order for the system to be effectively implementable. For instance, even if it turned out that people with certain diseases should be ineligible for organ transplants because their prospect of benefit is too poor, a policy of entirely excluding these people might produce a backlash from their family members that renders the entire policy less effective. Even if the exclusion really would be morally best, a second-best policy may be the only one that is achievable.

Considerations of implementability might be used to justify adding principles that would not be judged best after philosophical deliberation. To return to an example discussed above, Greg Bognar and Samuel Kerstein argue in favor of sickestfirst allocation on the basis that "Ignoring the present suffering of patients is likely to be hard for the public to accept especially in life-and-death cases, regardless of scarcity" (2010, p. 39). Similarly, a recent survey argues that "decisions in a democracy will not be sustainable in the long run unless legitimized by a majority" (Krütli, Rosemann, Tornblom, \& Smieszek, 2016). However, even though public preferences matter to implementability, balancing the implementability of an allocation system against its moral desirability can present difficult questions. An easily implementable but morally flawed system may not be preferable, all things considered, to a morally meritorious but difficult-to-implement system. 


\section{How Ethics Can Inform Social-Scientific Research on Fairness}

Surveys of public attitudes about fair allocation will be most relevant to normative questions if they ask respondents about allocation proposals that are compelling options from the standpoint of normative inquiry. However, most survey researchers receive little education in the methods of normative inquiry, just as most bioethicists receive little education in survey methods. Ethics education for survey researchers generally focuses on ensuring that survey participants give informed consent to participation and on avoiding harm to survey participants. The emphasis is on the ethics of conducting survey research, rather than on conducting survey research about ethics.

When surveys ask about normative questions, as opposed to factual questions, it is important for the surveys to reflect both expertise in the empirical methods of good survey design and expertise in thinking about and conceptualizing questions of value. Empirical expertise is important in ensuring that the surveys produce interpretable data, have sufficient statistical power, and can be conducted at reasonable cost. Ethical expertise is important in ensuring that the surveys are clear about which normative questions they are asking, and in analyzing the responses of qualitative interviewees and mapping them onto the normative landscape.

\section{Qualitative Research and the Elucidation of Normative Justifications}

Moral philosophers generally want to know not merely that people offer certain answers to questions of value, but why they offer those answers. Eliciting people's reasons and justifications for their answers is often more easily done using qualitative research methodologies, such as focus groups, document analysis, or ethnography, than by using quantitative surveys. However, quantitative surveys can also ask people about their justifications, even though they may be unable to bring out as much fine nuance as in-depth discussions.

One impressive, though dated, piece of empirical social science regarding fairness and allocation is the work of the Harvard political scientist Jennifer Hochschild. Hochschild (1981) begins her What's Fair?, a work examining public preferences regarding economic distribution, by reporting quantitative data regarding actual economic distributions, as well as public preferences regarding what economic distribution would be desirable. However, Hochschild spends the bulk of the book analyzing the transcripts of interviews with 28 respondents. She reports that:

This research method permitted respondents to reveal their convictions and uncertainties, their reasoning process and emotional reactions, their foci for passion and indifference, their expertise and ignorance. From the interviews, I was able to evaluate the content, complexity, and strength of individual beliefs about justice, as well as the circumstances in which they occurred and their effects on respondents' political and economic views (1981, p. 23). 
Hochschild goes on to explain how her qualitative methodology can add detail to a quantitative report of individual attitudes:

For example, polls show that most of the population usually does not support programs leading to the downward redistribution of wealth. Surveyors explain this finding through the correlation between wealth and support; the researcher interprets the relationship and infers that the rich do not support certain programs because these programs would hurt their economic position. Intensive interviewers explain this finding by discussing with respondents what they expect and how they would feel about the effect of redistributive programs on their lives. The researcher interprets respondents' statements to draw conclusions about what redistribution means to people in various economic positions (1981, p. 24).

Though Hochschild's research is not focused on the allocation of medical resources, but rather on distributive justice generally, the value of her methodology suggests the merit of similar research into individuals' justifications for their choices about the fair allocation of medical resources. It is also valuable to have extended and analyzed transcripts of some interviews - as Hochschild provides — rather than simply a coded summary of what the interviewer takes to be the respondent's reasons for her stated preferences.

\section{Quantitative Research and Question Wording}

Some quantitative studies have aimed to test the popularity of normative theories of medical ethics. For instance, one recent study attempted to provide quantitative data on the popularity of different principles for allocation among laypeople, general practitioners, and medical students (Krütli et al. 2016).

However, as the survey notes, its definition of "sickest first" allocation made comparison to the normative theory difficult, because it defined the sickest individuals as "those who need the organ most urgently" (Krütli et al. 2016). By building a concept of need into the definition of sickest-first, it may have implicitly taken a stance on the moral attractiveness of that principle.

The challenge of wording survey questions about normative issues in a way that is faithful to the moral theory under discussion suggests the desirability of increased work on perceptions of fairness by social scientists that integrates qualitative and quantitative methods and provides in-depth analysis of survey responses. Given the desirability of examining the ethical reasoning of survey respondents in depth, such research could be effectively conducted as a partnership between moral philosophers and social scientists.

\section{Conclusion}

The normative challenge of how to fairly allocate scarce medical resources is a perennial one. Advances in medicine have expanded our ability to save lives, and in so doing have turned unpreventable tragedies into moral dilemmas. Empirical 
research into public preferences for the allocation of scarce medical resources has tremendous value, both in illuminating questions and approaches for ethical analysis and in identifying strategies for making allocation systems implementable. While knowing what the public prefers does not entail an answer to how medical resources should be allocated, improved collaboration between bioethicists and empirical researchers could lead to more productive research programs both in ethics and in the social sciences.

Acknowledgements I am grateful to Ezekiel Emanuel, Alan Wertheimer, and Timo Smieszek for discussion of these issues, and to Meng Li, David Tracer, and an anonymous reviewer for their comments. Thanks to Kristen Miller for her help with the references.

\section{References}

Alexander, S. (1962). They decide who lives, who dies. Life, 102-125.

Alvarez, A. A. (2001). How rational should bioethics be? The value of empirical approaches. Bioethics, 15(5-6), 501-519.

Chappell, R. Y. (2016). Against 'saving lives': Equal concern and differential impact. Bioethics, 30(3), 159-164.

Cohen, G. A. (2009). Rescuing justice and equality (pp. 229-273). Cambridge, MA: Harvard University Press.

Egan, T. M., Murray, S., Bustami, R. T., Shearon, T. H., McCullough, K. P., Edwards, L. B., ... Grover F. L. (2006). Development of the new lung allocation system in the United States. American Journal of Transplantation, 6(5 Pt 2), 1212-1227.

Estlund, D. M. (1994). Opinion leaders, independence, and Condorcet's jury theorem. Theory and Decision, 36(2), 131-162.

Kamm, F. M. (2007). Intricate Ethics (p. 5). Oxford: Oxford UP.

Gamlund, E. (2016). What is so important about completing lives? A critique of the modified youngest first principle of scarce resource allocation. Theoretical Medicine and Bioethics, 37(2), 113-128.

Hochschild, J. L. (1981). What's fair?: American beliefs about distributive justice. Cambridge, MA: Harvard University Press.

Hope, T., Sprigings, D., \& Crisp, R. (1993). "Not clinically indicated": patients' interests or resource allocation? BMJ, 306(6874), 379-381.

Irving, M. J., Tong, A., Jan, S., Wong, G., Cass, A., Allen, R. D., et al. (2013). Community preferences for the allocation of deceased donor organs for transplantation: A focus group study. Nephrology, Dialysis, Transplantation: Official Publication of the European Dialysis and Transplant Association - European Renal Association, 28(8), 2187-2193.

Kerstein, S. J., \& Bognar, G. (2010). Complete lives in the balance. The American Journal of Bioethics, 10(4), 37-45.

Krohmal, B. J., \& Emanuel, E. J. (2007). Access and ability to pay: The ethics of a tiered health care system. Archives of Internal Medicine, 167(5), 433-437.

Krütli, P., Rosemann, T., Tornblom, K. Y., \& Smieszek, T. (2016). How to fairly allocate scarce medical resources: Ethical argumentation under scrutiny by health professionals and lay people. PloS One, 11(7), e0159086.

Lenton, A. P., Blair, I. V., \& Hastie, R. (2006). The influence of social categories and patient responsibility on health care allocation decisions: Bias or fairness? Basic and Applied Social Psychology, 28(1), 27-36. 
Lipsitch, M., Finelli, L., Heffernan, R. T., Leung, G. M., Redd, S. C., \& 2009 H1N1 Surveillance Group. (2011). Improving the evidence base for decision making during a pandemic: The example of 2009 influenza A/H1N1. Biosecurity and Bioterrorism: Biodefense Strategy, Practice, and Science, 9(2), 89-115.

Malakoff, D. (1999). Bayes offers a 'new' way to make sense of numbers. Science, 286(5444), 1460-1464.

McMillan, J., \& Hope, T. (2010). Balancing principles, QALYs, and the straw men of resource allocation. The American Journal of Bioethics, 10(4), 48-50.

Munson, J. C., Christie, J. D., \& Halpern, S. D. (2011). The societal impact of single versus bilateral lung transplantation for chronic obstructive pulmonary disease. American Journal of Respiratory and Critical Care Medicine, 184(11), 1282-1288.

Norheim, O. F. (2010). Priority to the young or to those with least lifetime health? The American Journal of Bioethics: AJOB, 10(4), 60-61.

Ottersen, T. (2013). Lifetime QALY prioritarianism in priority setting. Journal of Medical Ethics, 39(3), 175-180.

Persad, G., Wertheimer, A., \& Emanuel, E. J. (2009). Principles for allocation of scarce medical interventions. The Lancet, 373(9661), 423-431.

Rawls, J. (1999). A theory of justice. Cambridge, MA: Harvard University Press.

Rawls, J. (2005). Political liberalism (pp. 212-254). New York, NY: Columbia University Press.

Rid, A., \& Emanuel, E. J. (2014). Ethical considerations of experimental interventions in the Ebola outbreak. The Lancet, 384(9957), 1896-1899.

Smith, L. J., Anand, P., Benattayallah, A., \& Hodgson, T. L. (2015). An fMRI investigation of moral cognition in healthcare decision making. Journal of Neuroscience, Psychology, and Economics, 8(2), 116.

Strech, D., Synofzik, M., \& Marckmann, G. (2008). How physicians allocate scarce resources at the bedside: A systematic review of qualitative studies. Journal of Medicine and Philosophy, 33(1), 80-99.

Sulmasy, D. P., \& Sugarman, J. (2001). The many methods of medical ethics (or, thirteen ways of looking at a blackbird). In J. Sugarman \& D. P. Sulmasy (Eds.), Methods in medical ethics (2nd ed., pp. 3-18). Washington, DC: Georgetown University Press.

Tong, A., Howard, K., Jan, S., Cass, A., Rose, J., Chadban, S., ... Craig, J. C. (2010). Community preferences for the allocation of solid organs for transplantation: A systematic review. Transplantation, 89(7), 796-805.

Tong, A., Jan, S., Wong, G., Craig, J. C., Irving, M., Chadban, S., ... Howard, K. (2012). Patient preferences for the allocation of deceased donor kidneys for transplantation: A mixed methods study. BMC Nephrology, 13, 18.

Tong, A., Jan, S., Wong, G., Craig, J. C., Irving, M., Chadban, S., .. Howard, K. (2013). Rationing scarce organs for transplantation: Healthcare provider perspectives on wait-listing and organ allocation. Clinical Transplantation, 27(1), 60-71.

Vawter, D. E., Garrett, J. E., Gervais, K. G., Prehn, A. W., DeBruin, D. A., Tauer, C. A., ... Marshall, M. F. (2010). For the good of us all: Ethically rationing health resources in Minnesota in a severe influenza pandemic. Minneapolis, MN: Minnesota Center for Health Care Ethics and University of Minnesota Center for Bioethics.

Vawter, D. E., Gervais, K. G., \& Garrett, J. E. (2007). Allocating pandemic influenza vaccines in Minnesota: Recommendations of the pandemic influenza ethics work group. Vaccine, 25(35), $6522-6536$.

Yamin, A. E. (2009). Shades of dignity: Exploring the demands of equality in applying human rights frameworks to health. Health and Human Rights, 11(2), 1-18. 